\title{
Why are older adults and individuals with underlying chronic diseases in Germany not vaccinated against flu? A population-based study
}

\author{
Birte Bödeker ${ }^{1 *}$, Cornelius Remschmidt ${ }^{1}$, Patrick Schmich ${ }^{2}$ and Ole Wichmann ${ }^{1}$
}

\begin{abstract}
Background: Older adults and individuals with underlying chronic diseases are at increased risk of developing influenza-related complications and are target groups for seasonal influenza vaccination in many countries. In Germany, an annual national information campaign is conducted to increase influenza vaccination uptake in the target groups. However, data are lacking on knowledge and attitudes toward influenza vaccination among older adults and those with chronic diseases. The present study aimed to (i) estimate influenza vaccination uptake for the 2012/13 and 2013/14 seasons, (ii) assess knowledge and attitudes about influenza vaccination, and (iii) identify factors associated with vaccination uptake in two risk groups.

Methods: Between March and June 2014, we conducted a nationwide cross-sectional survey in adults ( $\geq 18$ years) living in Germany using computer-assisted telephone interviewing. We calculated weighted vaccination coverage rates in two at-risk groups. Group 1 comprised participants aged 18-59 years with underlying chronic diseases. Group 2 comprised participants aged 60+, irrespective of underlying disease. We used univariate and multivariable logistic regression analyses to identify associations between influenza vaccination uptake and sociodemographic characteristics, and to evaluate attitudes and knowledge.
\end{abstract}

Results: In total, 1,519 interviews were conducted. Seasonal influenza vaccination uptake in people with underlying chronic diseases aged 18-59 years was $24 \%$ in 2012/2013 and $23 \%$ in 2013/2014. In older adults, uptake was $50 \%$ and $49 \%$ in 2012/13 and 2013/14 respectively. There were considerable vaccination-related knowledge gaps among respondents. For example, about half of the participants who aged $\geq 60$ years and/or suffered from underlying chronic diseases believed that influenza vaccination could cause influenza. The most commonly stated reasons for not being immunized were mistrust of the vaccination (22\%) and the perception that influenza is not dangerous (21\%). For both groups, vaccination uptake was independently associated with sex, perceived severity of influenza, perceived vaccination effectiveness, and the perceived likelihood or severity of vaccination side effects. For older adults, additional factors influencing vaccination uptake were age, underlying chronic diseases, and recent advice through physician consultation.

Conclusions: Influenza vaccination coverage rates in Germany remain low. Individual perceptions regarding harms and benefits are crucial in the decision-making process. Communication strategies should focus on improving understanding and perception of personal risks arising from the disease and the vaccination.

Keywords: Germany, Influenza, Risk group, Vaccination attitude, Vaccination knowledge

\footnotetext{
* Correspondence: BoedekerB@rki.de

'Department for Infectious Disease Epidemiology, Immunization Unit, Robert Koch Institute, Seestraße 10, 13353 Berlin, Germany

Full list of author information is available at the end of the article
} 


\section{Background}

Older adults and people with underlying chronic diseases have an increased risk of developing severe influenza and influenza-related complications [1-3]. Therefore, the World Health Organization and National Immunization Technical Advisory Groups in most industrialized countries recommend seasonal influenza vaccination for these at-risk groups [4-6].

To reduce influenza-associated morbidity and mortality, European Union (EU) member states committed to the goal of attaining vaccination coverage of at least $75 \%$ for older age groups by 2014/15 [7]. However, thus far, only the Netherlands and the United Kingdom have achieved the $75 \%$ threshold for older adults, whereas other European countries, including Germany, are still below the projected target [8].

To raise awareness about the importance of influenza vaccination and to increase vaccination uptake, an annual national information campaign is conducted in Germany. Data on vaccination uptake in different target groups, and about knowledge of and attitudes toward vaccination are crucial to this campaign and the progress towards the EU vaccination coverage goal. As Germany has no central immunization registry, information on influenza vaccination coverage is predominantly available from population-based cross-sectional surveys [9] and from health assurance claims data [10]. However, data on attitudes and knowledge about seasonal influenza and vaccination in specific target groups are limited.

Therefore, we conducted a nationwide cross-sectional survey in Germany to (i) estimate influenza vaccination uptake in older adults and in individuals with underlying chronic diseases for the 2012/13 and 2013/14 seasons, (ii) assess attitudes toward and knowledge about seasonal influenza and seasonal influenza vaccination and (iii) identify factors associated with vaccination uptake in these two at-risk groups.

\section{Methods}

\section{Study design and population}

We conducted a nationwide cross-sectional survey between March and June 2014 using computer-assisted telephone interviewing. Inclusion criteria for participation were (i) being at least 18 years of age, (ii) Germanspeaking, and (iii) having a mobile or landline telephone. Telephone numbers were randomly generated using Waksberg's method [11], adapted by Gabler and Häder [12] for Germany and provided by the Leibniz Institute for the Social Sciences (GESIS) in Mannheim, Germany. People who were reached by landline were selected by last-birthday-method [13]. For the mobile phone sample, interviews were conducted with the person who answered the phone. Calls took place Mondays through Fridays from 9:30 a.m. to 2:30 p.m. and from 3:00 p.m. to 8:00 p.m., and Saturdays from 10:00 a.m. to 3:00 p.m. If the number dialed gave a busy signal or rang but was unanswered, up to 10 further attempts were made to contact the number. The management of telephone calls and call-backs was automatically regulated by the computer-assisted telephone interviewing software Voxco CC3 (10.3, Montreal, Canada). The interviews were conducted in German by trained interviewers from the Robert Koch Institute.

According to a sample size calculation, 760 subjects $\geq 60$ years were needed to estimate a coverage of $48 \%$ (vaccination rate in 2009/10 in this age group [14]) with a confidence interval of $95 \%$ and an error estimate of $5 \%$. Response and Cooperation Rates 3 were calculated as defined by the American Association for Public Opinion Research (AAPOR) [15].

\section{Questionnaire}

We used a structured an pre-tested questionnaire that collected data on (i) behavior, attitudes and knowledge about seasonal influenza vaccination and influenza disease, (ii) information behavior concerning influenza immunization, and (iii) sociodemographic factors. The majority of survey items had been used in previous studies conducted by the Robert Koch Institute $[9,16]$ but were adapted to our study sample and design. All questions were self-reported and not validated.

Influenza vaccination uptake in 2012/13 and/or 2013/ 14 was defined as having received a flu shot in the respective season. Additionally, information on the influenza vaccination status for each child living in the respective household of the participant was collected for the 2013/14 season. To assess influenza and vaccinationrelated knowledge, we asked participants to agree/disagree or state "don't know" to specific statements. We assumed that a lack of knowledge (don't know) reflected a lack of awareness about the importance of obtaining vaccination; therefore, don't know was defined as an incorrect answer.

We used 10-point Likert-scales to assess perceived probability of acquiring influenza disease and probability of severe side effects following vaccination ("not likely" to "very likely"), perceived severity of the influenza disease and perceived severity of vaccination side effects ("not serious" to "very serious") as well as perceived vaccination effectiveness ("not effective" to "very effective").

For sociodemographic factors, we collected data on age, sex, place of residence, education level, migration background and chronic illnesses such as diabetes, stroke, cardiovascular diseases, renal failure, liver diseases, cancer, chronic neurologic disease, immune deficiency, bronchitis, or asthma. Migration background was defined as described by Schenk et al. based on parents' country of birth [17]. A participant was defined as chronically ill if any of 
the above mentioned diseases had been diagnosed by a physician during their lifetime.

Participants who were $\geq 60$ years of age and/or suffered from underlying chronic diseases were regarded as at-risk.

\section{Statistical analysis}

To control for possible sampling and selection biases, the sample was weighted to match national general population parameters. The basic weighting parameters were derived from the Federal Statistical Office of Germany for 2011 [18] and included the geographical region, age, sex, and education. All results are presented as weighted data unless otherwise stated.

Descriptive statistics were applied to describe sociodemographic characteristics, vaccination coverage, reasons for not being vaccinated, information behavior, and attitude and knowledge characteristics. We used Pearson's chi-square test to compare vaccination- and influenzarelated knowledge items between vaccinated and unvaccinated at-risk participants. Additionally, we conducted stratified univariate and multivariable logistic regression analyses to determine potential associations between influenza vaccination uptake and sociodemographic characteristics, attitude and knowledge items. For this purpose we stratified the study population into two subgroups. Group 1 consisted of people aged 18-59 years with underlying chronic diseases. Group 2 comprised people aged $\geq 60$ years, irrespective of whether they had an underlying chronic disease. Odds ratios (OR) and $95 \%$ confidence intervals $(\mathrm{CI})$ were calculated. A $p$-value of $<0.05$ was considered statistically significant. Variables with a $p$-value of $\leq 0.1$ in the univariate analysis were entered in the first step of the multivariable analyses. We then removed non-significant factors $(\geq 0.05)$ from the model in a stepwise backward procedure to obtain the final model. Although they were not significant in the final model, sex, age and education variables were included a priori and were not removed. Additionally, an interaction term (sex\#chronic disease) was included in the final model for older adults. Missing data were not replaced or imputed. Statistical analyses were performed with StataSE13 (StataCorp LP, College Station, TX, USA) using complex survey methods.

\section{Ethical considerations and data protection}

Participants were informed about study details, including data protection and privacy issues. Verbal consent was required for participants to be included in the study. Telephone numbers were generated randomly and were deleted directly after the interview. The study was approved by the German Federal Commissioner for Data Protection and Freedom of Information. All data were collected and analyzed anonymously.

\section{Results}

\section{Recruitment and sample characteristics}

In total, 1,519 participants were interviewed. The Response Rate 3 was $16.2 \%$ and the Cooperation Rate 3 was $28.7 \%$. An overview of the study population characteristics is presented in Table 1. Overall, $55.1 \%$ (95 \% CI 51.6-58.5) of the participants were aged $\geq 60$ years and/ or had an underlying chronic disease.

\section{Vaccination coverage}

Influenza vaccination status was available for almost all participants (2012/13: 98.6 \%; 2013/14: $99.9 \%)$. Vaccination rates for the 2012/13 and 2013/14 seasons by sex, age, underlying chronic disease and residency are presented in Table 2. Overall, more than $25 \%$ of participants (at risk and not at risk) were vaccinated against seasonal influenza. Of those who received the flu shot in 2012/13, 70.8 \% (95 \% CI 64.8-76.2) were also vaccinated the following season. In 2012/13 vaccination uptake in Group 2 participants (those aged $\geq 60$ years) was $50.0 \%$, and in 2013/14 uptake was $49.4 \%$. For those aged $\geq 65$ years, coverage was $53.1 \%$ in both seasons

Table 1 Characteristics of the study sample, Germany, 2014

\begin{tabular}{ll}
\hline & $\begin{array}{l}\text { Study population \% } \\
(95 \% \text { Cl) }\end{array}$ \\
\hline Sex $(n=1,519)$ & \\
Male & $47.6(44.2-51.0)$ \\
Female & $52.5(49.0-55.8)$ \\
Age $(n=1,519)$ & \\
$18-39$ years & $31.5(28.3-35.0)$ \\
$40-59$ years & $33.1(29.9-36.4)$ \\
$60-69$ years & $16.3(14.2-18.5)$ \\
$70-79$ years & $14.3(12.3-16.6)$ \\
$\geq 80$ years & $4.8(3.7-6.2)$ \\
Geographic region $(n=1,512)^{\mathrm{b}}$ & \\
Eastern Federal States & $19.1(16.7-21.7)$ \\
Western Federal States & $80.9(78.3-83.3)$ \\
Underlying chronic disease $(n=1,501)$ & $41.1(37.8-44.5)$ \\
$<60$ years and underlying chronic disease $(n=694)$ & $30.0(25.9-34.4)$ \\
$\geq 60$ years and underlying chronic disease $(n=807)$ & $61.2(56.4-65.8)$ \\
Migration background $(n=1,497)$ & $16.2(13.8-19.0)$ \\
Education level $(n=1,495)^{c}$ & \\
Low & $39.7(36.2-43.3)$ \\
Middle & $28.9(26.0-32.1)$ \\
High & $31.4(28.6-34.3)$ \\
\hline
\end{tabular}

${ }^{a}$ Weighted data (totals are not weighted)

${ }^{b}$ Eastern Federal States: Mecklenburg-Vorpommern, Brandenburg, Berlin, Saxony, Saxony-Anhalt, Thuringia; Western Federal States: Schleswig-Holstein, Bremen, Hamburg, Lower Saxony, Hesse, Rhineland-Palatinate, Saarland, North Rhine-Westphalia, Bavaria, Baden-Württemberg

' Low: 9 years or less of school education; Middle: at least 10 years of school education; High: university entrance diploma 
Table 2 Influenza vaccination uptake in 2012/13 and 2013/14

\begin{tabular}{lll}
\hline & $2012 / 13 \%(95 \% \mathrm{Cl})^{\mathrm{a}}$ & $2013 / 14 \%(95 \% \mathrm{Cl})^{\mathrm{a}}$ \\
\hline $\begin{array}{l}\text { Total } \\
\text { Sex }\end{array}$ & $30.2(27.3-33.4)$ & $26.6(23.8-29.6)$ \\
$\quad$ Male & $29.4(25.2-34.1)$ & $22.0(18.5-26.0)$ \\
$\quad$ Female & $31.0(26.9-35.3)$ & $30.8(26.7-35.1)$ \\
Age & & \\
18-39 years & $15.3(10.8-21.3)$ & $9.9(6.7-14.6)$ \\
40-59 years & $23.3(18.8-28.7)$ & $18.2(14.1-23.2)$ \\
$\geq 60$ years & $50.0(45.2-54.8)$ & $49.4(44.6-54.2)$ \\
$\quad 60-69$ years & $40.6(34.1-47.4)$ & $39.4(32.9-46.3)$ \\
$\quad 70-79$ years & $58.5(50.7-66.0)$ & $59.2(51.4-66.5)$ \\
$\quad \geq 80$ years & $55.7(42.5-68.1)$ & $53.5(40.5-66.0)$ \\
Underlying chronic disease & & \\
Yes & $41.5(36.5-46.7)$ & $40.4(35.4-45.6)$ \\
$\quad<60$ years & $24.1(17.8-31.9)$ & $22.6(16.4-30.2)$ \\
$\quad \geq 60$ years & $56.6(50.3-62.7)$ & $56.3(50.1-62.3)$ \\
No & $23.0(19.5-27.0)$ & $17.4(14.5-20.8)$ \\
$\quad<60$ years & $17.7(13.9-22.4)$ & $11.0(8.2-14.6)$ \\
$\geq 60$ years & $40.5(33.2-48.2)$ & $38.4(31.3-46.0)$ \\
Place of residence & & $38.7(32.1-45.6)$ \\
Western Federal States & $44.4(37.5-51.5)$ & $23.5(20.6-26.7)$ \\
\hline
\end{tabular}

${ }^{a}$ Weighted data

(95 \% CI 47.3-58.8 and 47.4-58.8 for 2012/13 and 2013/ 14 , respectively). Vaccination coverage increased with age and was highest in persons aged 70-79 years.

Of participants in Group 1 (people aged 18-59 years with underlying chronic diseases), $24.1 \%$ were vaccinated in 2012/13 and $22.6 \%$ in 2013/14. Overall, vaccination coverage declined between 2012/13 and 2013/14. The greatest decrease was observed among people not belonging to the vaccination target group (aged 18-59 without underlying chronic diseases).

Vaccination status was available for 431 children (95.8\%), of which $15.1 \%$ (95\% CI 11.8-18.8, crude without weighting) were vaccinated against seasonal influenza. Of all sampled children, $6.7 \%$ (95 \% CI 4.6-9.5, crude without weighting) suffered from an underlying chronic disease and of these, $24.1 \%$ (95 \% CI 10.3-43.5, crude without weighting) were vaccinated during the 2013/14 season. Participants who received a flu shot in 2013/14 were more likely to have at least one child vaccinated in their household than unvaccinated participants (44.3\% vs. $13.4 \%$, respectively, $p<0.001)$.

\section{Reasons for not being immunized}

In all unvaccinated participants (at risk and not at risk), the most frequently stated reasons for not having received an influenza vaccination were a perception of being at low risk for influenza disease (26.7 \%, $95 \%$ CI 23.3-30.5), not having thought about influenza vaccination yet $(21.5 \%, 95 \%$ CI 18.1-25.3) and mistrust of the vaccination (18.3\%, $95 \%$ CI 15.5-21.5). Moreover, 9.8 \% (95\% CI 7.8-12.3) of unvaccinated participants opposed vaccination in general (7.2\% of all participants, $95 \%$ CI 5.7-9.0). Among the vaccination opponents, older people rejected vaccination more frequently than younger people (participants <60 years: $7.8 \%$ vs. participants $\geq 60$ years: $15.9 \%, p<0.05$ ).

Among at-risk participants, the most commonly stated reasons for not being vaccinated were (Fig. 1) mistrust of the vaccination $(22.3 \%)$, perception of low risk for influenza disease $(21.2 \%)$, and not having thought about influenza immunization yet (14.9\%). Of all participants, $5.5 \%$ (95\% CI 3.1-9.5) of those $\geq 60$ years and $9.7 \%$ (95\% CI 6.1-15.1) of the chronically ill (independent of age) did not know that they belonged to a group for whom seasonal influenza vaccination is recommended.

Participants who were not at-risk felt that influenza was not a dangerous disease and considered not getting vaccinated more often than at-risk participants $(31.3 \%$ vs. $21.2 \%, p<0.05$ and $26.0 \%$ vs. $14.9 \%, p<0.05$, respectively). Interestingly, at-risk participants reported mistrust of the vaccination, health issues that deterred them from vaccination and opposing vaccination in general more often than not at-risk participants $(22.3 \%$ vs. $15.5 \%, p<0.05,13.5 \%$ vs. $3.5 \%, p<0.001$ and $12.5 \%$ vs. $7.8 \%, p<0.05$, respectively).

\section{Information seeking behavior}

Of all participants (at risk and not at risk), $25.5 \%$ (95\% CI 22.6-28.8) reported a need for further influenza vaccination-related information. Among at-risk participants, $22.1 \%$ (95 \% CI 18.5-26.1) stated an information demand. They were particularly interested in information on vaccination-related side effects $(76.4 \%$, $95 \% \mathrm{CI}$ 67.3-83.6) and potential influenza-associated complications (61.4 \%, 95 \% CI 51.4-70.5). At-risk participants preferred to receive information from their physicians (67.7 \%, 95 \% CI 58.0-76.1).

\section{Influenza- and vaccination-related attitudes and knowledge} Among at-risk participants, the perceived probability of becoming infected with influenza was higher than the fear of vaccination side-effects (median: 5 vs. 3; both ranges: $1-10)$. In contrast, the perceived severity of influenza disease was identical to the perceived severity of possible vaccination side-effects (median: 5, range: 1-10 for both groups). The perceived effectiveness of seasonal influenza vaccination was higher among at-risk participants than those not at-risk (median: 6 vs. 5, both ranges: $1-10$ ).

Differences in vaccination- and disease-related knowledge between unvaccinated and vaccinated at-risk participants 


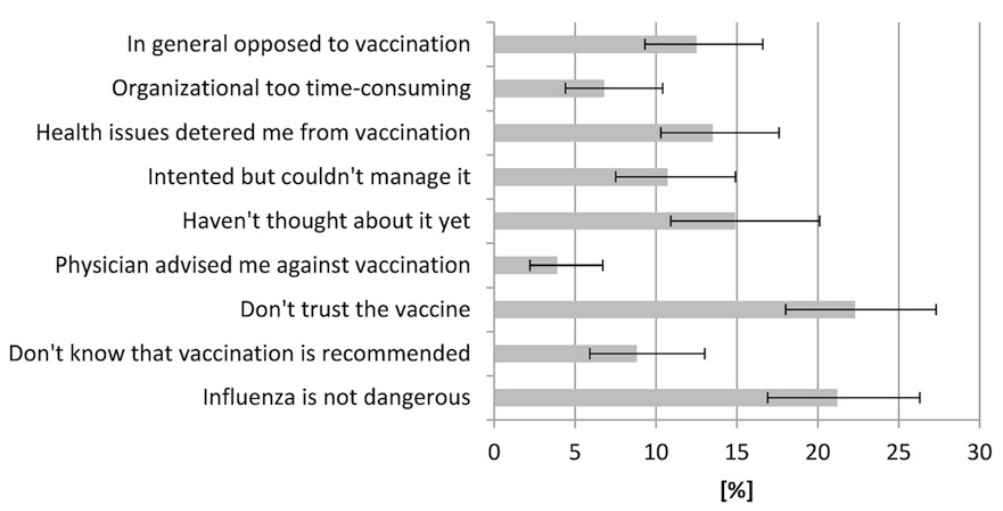

Fig. 1 Reasons against seasonal influenza vaccination given by unvaccinated at-risk participants $(n=586)$, Germany, 2014 (weighted data; multiple answers were allowed)

are presented in Table 3. Independent of vaccination status, $53.8 \%$ (95\% CI 49.4-58.1) of at-risk participants believed that vaccination could cause an infection. The results showed that vaccinated at-risk participants agreed that the vaccination could not cause influenza infection more often than unvaccinated at-risk participants (58.2\% vs. $38.5 \%$, respectively, $p<0.001)$.

\section{Factors associated with vaccination uptake in individuals aged 18-59 years with underlying chronic diseases (Group 1) and older adults (Group 2)}

Tables 4 and 5 present the results of the univariate and multivariable logistic regression analyses of factors influencing vaccination uptake in participants in Group 1 and Group 2 for the 2013/14 season. For both risk groups, influenza vaccination uptake was independently associated with sex, perceived severity of influenza, and perceived vaccination effectiveness. In Group 1, vaccination uptake was negatively associated with perceived severity of vaccination side effects and in Group 2 uptake was negatively associated with perceived probability of vaccination side effects. For participants in Group 2, being advised of the influenza vaccination through physician consultation in the last six months and having an underlying chronic disease were further promoters of vaccination uptake. The interaction term in the final model for older adults indicated that being female in addition to an underlying chronic disease influenced vaccination uptake, showing that women without underlying chronic disease were more often vaccinated than healthy men.

\section{Discussion}

Our study aimed to estimate seasonal influenza vaccination uptake in people aged $\geq 60$ years and in people with underlying chronic diseases in Germany. Furthermore, influenza-related attitudes and knowledge, as well as factors influencing vaccination decision-making were analyzed. Our results revealed that vaccination coverage remained suboptimal for at-risk groups in Germany:

Table 3 Influenza- and influenza vaccination-related knowledge among unvaccinated $(n=429)$ and vaccinated $(n=586)$ at-risk participants, Germany 2014

\begin{tabular}{|c|c|c|c|}
\hline & Vaccination status & $\begin{array}{l}\text { Agreement \% } \\
(95 \% \text { Cl) })^{a}\end{array}$ & $p$-value \\
\hline \multirow[t]{2}{*}{ Coughing or sneezing inside of the elbow can reduce the risk of influenza infection } & Not vaccinated & 68.7 (62.9-73.9) & - \\
\hline & Vaccinated & $72.4(66.5-77.7)$ & $\geq 0.05$ \\
\hline \multirow[t]{2}{*}{ Regular hand-washing with soap can reduce the risk of influenza infection } & Not vaccinated & $91.7(87.7-94.5)$ & - \\
\hline & Vaccinated & 93.9 (88.7-96.8) & $\geq 0.05$ \\
\hline \multirow[t]{2}{*}{ Vaccination cannot cause influenza infection } & Not vaccinated & $38.5(33.1-44.3)$ & - \\
\hline & Vaccinated & $58.2(51.5-64.6)$ & $<0.01 * *$ \\
\hline \multirow[t]{2}{*}{ Vaccination protects people in close surroundings } & Not vaccinated & $44.4(38.7-50.2)$ & - \\
\hline & Vaccinated & $55.2(48.5-61.8)$ & $<0.05 *$ \\
\hline \multirow[t]{2}{*}{ After immunization or infection with influenza, vaccination in subsequent influenza season is necessary } & Not vaccinated & $74.3(68.8-79.1)$ & - \\
\hline & Vaccinated & 79.7 (73.5-84.8) & $\geq 0.05$ \\
\hline
\end{tabular}

\footnotetext{
${ }^{a}$ Weighted data
}

${ }^{*} p<0.05 ;{ }^{* *} p<0.001$ 
Table 4 Factors associated with influenza vaccination uptake in people aged 18-59 years with underlying chronic diseases, Germany, 2013/14 influenza season

\begin{tabular}{|c|c|c|c|}
\hline & Vaccination coverage $\%^{\mathrm{a}, \mathrm{b}}$ & $\begin{array}{l}\text { Univariate OR } \\
(95 \% \mathrm{Cl})^{\text {a, b }}\end{array}$ & $\begin{array}{l}\text { Multivariable OR } \\
(95 \% \mathrm{Cl})^{\mathrm{a}, c}\end{array}$ \\
\hline \multicolumn{4}{|l|}{ Sex } \\
\hline Female & 27.4 & $1.80(0.81-4.02)$ & $4.07(1.50-11.03)$ \\
\hline Male & 17.3 & Ref. & Ref. \\
\hline \multicolumn{4}{|l|}{ Place of residence } \\
\hline Eastern Federal States & 33.2 & $2.18(0.92-5.17)$ & NS \\
\hline Western Federal States & 18.6 & Ref. & \\
\hline \multicolumn{4}{|l|}{ Age } \\
\hline 18-39 years & 18.4 & NS & NS \\
\hline $40-59$ years & 24.7 & & \\
\hline \multicolumn{4}{|l|}{ Education level } \\
\hline Low & 24.2 & NS & NS \\
\hline Middle & 24.6 & & \\
\hline High & 19.1 & & \\
\hline \multicolumn{4}{|l|}{ Vaccination cannot cause influenza infection } \\
\hline Agreed & 27.9 & $1.82(0.82-4.08)$ & NS \\
\hline Disagreed & 17.5 & Ref. & \\
\hline \multicolumn{4}{|l|}{ Coughing or sneezing inside of the elbow can reduce the risk of influenza infection } \\
\hline Agreed & 26.0 & $2.18(0.95-4.97)$ & NS \\
\hline Disagreed & 13.9 & Ref. & \\
\hline Perceived probability of getting infected with influenza when not immunized & - & $1.28(1.07-1.53)$ & NS \\
\hline Perceived severity of influenza when not immunized & - & $1.58(1.18-2.13)$ & $1.40(1.07-1.85)$ \\
\hline Perceived vaccination effectiveness & - & $1.39(1.19-1.62)$ & $1.25(1.03-1.52)$ \\
\hline Perceived severity of side effects following vaccination & - & $0.75(0.63-0.89)$ & $0.71(0.57-0.88)$ \\
\hline Perceived probability of severe side effects following vaccination & - & $0.70(0.55-0.89)$ & NS \\
\hline
\end{tabular}

Other nonsignificant variables in univariate analysis $(p>0.1)$ were: migration, being advised of the influenza vaccine through physician consultation in the last 6 months, and items focusing on influenza- and vaccine-related knowledge

${ }^{a}$ Weighted data; ${ }^{b}$ Included participants with information on relevant item; ${ }^{\text {Included }} n=166$ participants with complete information on all items; NS not significant, Ref. reference category

Only $49 \%$ of older adults and $23 \%$ of chronically ill people aged 18-59 years were vaccinated in 2013/14.

Our findings on vaccination coverage rates are consistent with results from other European countries [6, 8]. Only the United Kingdom and the Netherlands have achieved the EU goal of $75 \%$ vaccination coverage for older adults [8]. The different vaccination rates between EU countries might be explained by different communication activities supporting the vaccination recommendations, differences in vaccination systems and funding schemes, and also in different attitudes related to seasonal influenza vaccination. In England, general practitioners and other providers are encouraged to contact eligible patients in September and invite them to attend the clinic for vaccination [19]. However, because study methodologies differed (telephone survey vs. computerized immunization registries and clinical records), such differences in vaccination uptake must be interpreted with caution.

Compared to previous seasons, influenza vaccination uptake in at-risk groups decreased slightly in Germany, although this result was not statistically significant. Results of the nationwide survey German Health Update showed a vaccination coverage of $54 \%$ in people aged $\geq 60$ years in $2010 / 11$ and $53 \%$ in 2011/12. For people aged 18-59 years with underlying chronic diseases, vaccination uptake was $30 \%$ in $2010 / 11$ and $25 \%$ in 2011/12 [20]. A decrease in influenza vaccination coverage in at-risk people has also been observed in other European countries after the 2009/ 10 pandemic [21-24]. A Spanish study found a decrease in vaccination coverage in older adults from $69 \%$ in 2009/ 10 to $57 \%$ in 2012/13 [25]. However, in countries such as England, no decrease in coverage was observed [26]. In our study, the strongest decrease in vaccination coverage 
Table 5 Factors associated with influenza vaccination uptake in people aged $\geq 60$ years, Germany, 2013/14 influenza season

\begin{tabular}{|c|c|c|c|}
\hline & Vaccination coverage $\%^{\mathrm{a}}$, b & $\begin{array}{l}\text { Univariate OR } \\
(95 \% \mathrm{Cl})^{\mathrm{a}, \mathrm{b}}\end{array}$ & $\begin{array}{l}\text { Multivariable OR } \\
(95 \% \mathrm{Cl})^{\text {a, c }}\end{array}$ \\
\hline \multicolumn{4}{|l|}{ Sex } \\
\hline Female & 53.4 & $1.43(0.97-2.11)$ & - \\
\hline Male & 44.4 & Ref. & \\
\hline \multicolumn{4}{|l|}{ Underlying chronic disease } \\
\hline Yes & 56.3 & $2.07(1.39-3.09)$ & - \\
\hline No & 38.4 & Ref. & \\
\hline \multicolumn{4}{|l|}{ Sex and chronic disease $e^{e}$} \\
\hline Male and no chronic disease & 28.2 & - & Ref. \\
\hline Male and chronic disease & 54.1 & & $2.10(0.81-5.43)$ \\
\hline Female and no chronic disease & 46.6 & & $4.80(1.72-13.43)$ \\
\hline Female and chronic disease & 58.1 & & $2.13(0.73-6.19)$ \\
\hline \multicolumn{4}{|l|}{ Place of residence } \\
\hline Eastern Federal States & 62.8 & $1.97(1.26-3.10)$ & NS \\
\hline Western Federal States & 46.1 & Ref. & \\
\hline \multicolumn{4}{|l|}{ Age } \\
\hline $60-69$ years & 39.4 & Ref. & Ref. \\
\hline 70-79 years & 59.2 & $2.23(1.46-3.40)$ & $2.67(1.42-5.03)$ \\
\hline$\geq 80$ years & 53.5 & $1.77(0.97-3.20)$ & $1.89(0.73-4.89)$ \\
\hline \multicolumn{4}{|l|}{ Education level } \\
\hline Low & 51.9 & Ref. & NS \\
\hline Middle & 43.5 & $0.71(0.47-1.08)$ & \\
\hline High & 43.8 & $0.72(0.49-1.06)$ & \\
\hline \multicolumn{4}{|c|}{ Being advised of the influenza vaccination through physician consultation in the last 6 months } \\
\hline Yes & 63.0 & $2.87(1.89-4.37)$ & $2.63(1.44-4.84)$ \\
\hline No & 37.2 & Ref. & Ref. \\
\hline \multicolumn{4}{|l|}{ Vaccination cannot cause influenza infection } \\
\hline Agreed & 62.0 & $2.62(1.77-3.90)$ & NS \\
\hline Disagreed & 38.4 & Ref. & \\
\hline \multicolumn{4}{|l|}{ Vaccination protects people in close surroundings } \\
\hline Agreed & 54.9 & $1.57(1.06-2.33)$ & NS \\
\hline Disagreed & 43.6 & Ref. & \\
\hline \multicolumn{4}{|c|}{ After immunization or infection with influenza, vaccination in subsequent influenza season is necessary } \\
\hline Agreed & 52.5 & $1.64(1.02-2.63)$ & NS \\
\hline Disagreed & 40.3 & Ref. & \\
\hline Perceived probability of getting infected with influenza when not immunized & - & $1.44(1.28-1.61)$ & NS \\
\hline Perceived severity of influenza when not immunized & - & $1.56(1.41-1.71)$ & $1.31(1.13-1.52)$ \\
\hline Perceived vaccination effectiveness & - & $1.59(1.45-1.74)$ & $1.42(1.24-1.62)$ \\
\hline Perceived severity of side effects following vaccination & - & $0.83(0.76-0.90)$ & NS \\
\hline Perceived probability of severe side effects following vaccination & - & $0.77(0.70-0.85)$ & $0.69(0.61-0.80)$ \\
\hline
\end{tabular}

Other nonsignificant variables in univariate analysis $(p>0.1)$ were: migration and items focusing on influenza- and vaccination-related knowledge ${ }^{a}$ Weighted data; ${ }^{b}$ Included participants with information on relevant item; ${ }^{C}$ Included $n=550$ participants with complete information on all items; NS not significant; Ref. reference category; ${ }^{e} p$-value for interaction between sex ${ }^{*}$ chronic disease: 0.012 
was identified in individuals who did not belong to a vaccination target group: Vaccination uptake in healthy individuals aged $18-59$ years declined from $18 \%$ in 2012/13 to $11 \%$ in $2013 / 14$. Perceived low vaccination effectiveness, a perception of being at low risk for influenza disease, the fact that many people indicated that they had not yet thought about influenza vaccination, higher skepticism about vaccination after the pandemic season, and an initial influenza vaccination shortage in the 2013/14 season may have influenced their vaccination decision-making process more strongly than people who belonged to an at-risk group [27, 28, 14].

In at-risk people, the most commonly stated reasons against having received a flu shot were mistrust of the vaccination, a perception of being at low risk for influenza disease, and the fact that they had not yet thought about vaccination. These results were consistent with the findings of studies from other industrialized countries [29-35]. A Canadian study found that the most commonly reported reason to opt out of influenza vaccination in people aged $\geq 60$ years and people with chronic medical conditions were low perceived susceptibility to influenza or low perceived severity of the infection, as well as a lack of interest, and lack of time or information [29]. Another study found that in Germany, forgetfulness was a primary barrier to influenza vaccination [30].

It is concerning that almost $10 \%$ of all unvaccinated participants stated that they were opposed to vaccination in general ( $7 \%$ of all participants). This was particularly true for older adults. In Germany, it has been estimated that $3-5 \%$ of the population rejects immunizations in general [36] and one study found that $31 \%$ had some prejudice against particular vaccines [37]. Results from another German study showed that overall, older adults perceived vaccinations as less important than younger people [35]. However, because our study focused on influenza vaccination, we could not rule out that some participants may have mistakenly referred the question to the influenza vaccination itself instead of vaccinations in general. Therefore, this result must be interpreted with caution.

With regard to factors associated with influenza vaccination uptake in older adults and people aged $18-59$ years with chronic diseases, our results were similar for both target groups. In agreement with other studies, our analysis suggested that age and health conditions as well as perceptions relating to the disease and the vaccination were predictors of influenza vaccination status [32, 38-43].

We were not able to observe any association between influenza- und vaccination-related knowledge and vaccination uptake. A Canadian study suggested that knowledge played a smaller role in the vaccination decision-making process than beliefs concerning risk perception and vaccination effectiveness [33]. Betsch et al. found that the perceived risks of influenza disease and vaccination were key drivers of vaccination intention rather than cognitive risk estimation $[44,45]$. Finally, a similar finding was demonstrated by Brewer et al. [46] who supported the assertion that risk was the main predictor of vaccination behavior.

Our analyses revealed a potential association between vaccination uptake and being advised about the influenza vaccine through consultation with a physician. However, it is interesting that this was only observed among older adults. Other studies have also showed that the physician recommendation is a crucial facilitator in the vaccination decision-making process but it remains unclear whether the patients' age might play an addition role $[47,48,32,42]$. The fact that some participants did not know that influenza vaccination is recommended for them and mentioned physicians as the desired source of influenza- and vaccination-related information underlines the important role of physicians in obtaining high vaccination coverage.

Our study has some potential limitations: (i) The response and cooperation rates as defined by AAPOR [15] were low at 16.2 and $28.7 \%$, respectively. However, because of our study design (using mobile and landline telephones and a complex weighting procedure), it can be assumed that data quality is good overall in terms of generalizability to the German population. However, we cannot rule out some degree of selection bias. (ii) Information on chronic underlying diseases and vaccination uptake were self-reported and could therefore be subject to misclassification. While a recently published study suggested an overestimation for self-reported seasonal influenza vaccination rates compared to vaccination registries [25] other studies found an adequate degree of reliability $[49,50]$. Therefore, it can be assumed that vaccination coverage rates in our study population are rather overestimated. (iii) The sample was limited to the German-speaking population as the interviews were carried out in German. People who were not able to understand or speak German were therefore not represented in the study population, which might have introduced selection bias.

\section{Conclusion}

In conclusion, our study results indicated suboptimal seasonal influenza vaccination coverage in Germany for people aged $\geq 60$ years and those with underlying chronic diseases. Compared with previous seasons, vaccination coverage in at-risk groups remained stable, while coverage in the healthy population decreased considerably. While knowledge on disease- or vaccination-related issues did not influence vaccination decisions, perceptions of the disease severity and vaccination effectiveness as well as perceived likelihood and severity of vaccination 
side effects were key drivers for increased vaccination uptake. Additionally, many at-risk people had not thought about receiving a flu shot. Implementing reminder systems could therefore be helpful [51, 52]. As personal beliefs are crucial in the vaccination decision-making process, tailored communication strategies should focus on improving understanding about and perception of personal risks concerning the disease and the vaccination in the vaccination target groups.

\section{Competing interests}

The authors declare that they have no competing interest.

\section{Authors' contributions}

All authors were involved in the conception and design of the study. BB assisted in study design, performed the data analysis and drafted the manuscript. CR critically reviewed the manuscript and contributed substantially to the interpretation of study results and to the discussion. PS participated in the study design and coordination and reviewed the manuscript. OW conceptualized and supervised the study, critically reviewed the manuscript and contributed substantially to the writing of the manuscript and the interpretation of study results. All authors read and approved the final manuscript.

\section{Acknowledgements}

We would like to thank all those who participated in the study, Kristin Tolksdorf (Robert Koch Institute) for her statistical advice, and Oliver Ommen (Federal Centre for Health Education) for his support in the questionnaire development. The study was funded by internal funds of the Robert Koch Institute.

\section{Author details}

${ }^{1}$ Department for Infectious Disease Epidemiology, Immunization Unit, Robert Koch Institute, Seestraße 10, 13353 Berlin, Germany. ${ }^{2}$ Department of Epidemiology and Health Monitoring, Division of Health Interview Surveys and European Cooperation, Robert Koch Institute, General-Pape-Straße 62-66, 12101 Berlin, Germany.

Received: 3 March 2015 Accepted: 25 June 2015

Published online: 07 July 2015

\section{References}

1. Mertz D, Kim TH, Johnstone J, Lam PP, Science M, Kuster SP, et al. Populations at risk for severe or complicated influenza illness: systematic review and meta-analysis. BMJ. 2013;347:f5061.

2. Uyeki TM. Preventing and controlling influenza with available interventions. N Engl J Med. 2014;370(9):789-91.

3. Mazick A, Gergonne B, Nielsen J, Wuillaume F, Virtanen MJ, Fouillet A, et al. Excess mortality among the elderly in 12 European countries, February and March 2012. Euro Surveill. 2012;17(14):pii=20138.

4. World Health Organization. Meeting of the strategic advisory group of experts on immunization, April 2012 - conclusions and recommendations. Wkly Epidemiol Rec. 2012;21(87):201-16.

5. Robert Koch Institute. Mitteilung der Ständigen Impfkommission am Robert Koch-Institut: Empfehlungen der Ständigen Impfkommission (STIKO) am Robert Koch-Institut/Stand: August 2014. Epid Bulletin. 2014;34:305-40.

6. Mereckiene J, Cotter S, Nicoll A, Lopalco PL, Noori T, Weber JT, et al. Seasonal influenza immunisation in Europe. Overview of recommendations and vaccination coverage for three seasons: pre-pandemic (2008/09), pandemic (2009/10) and post-pandemic (2010/11). Euro Surveill. 2014;19(16):20780.

7. Council of the European Union. Council Recommendation of 22 December 2009 on seasonal influenza vaccination (2009/1019/EU). Off J Eur Union 2009. p. 71-2. http://www.epha.org/IMG/pdf/Council_Reccomendation_on_ seasonal_flu_vaccine.pdf. Accessed 30 Jun 2015.

8. European Centre for Disease Prevention and Control. Seasonal influenza vaccination in Europe - Overview of vaccination recommendations and coverage rates in the EU Member States for the 2012-13 influenza season. 2015. http://ecdc.europa.eu/en/publications/Publications/Seasonal-influenzavaccination-Europe-2012-13.pdf. Accessed 11 Feb 2015
9. Robert Koch Institute. Daten und Fakten: Ergebnisse der Studie "Gesundheit in Deutschland aktuell 2012". 2014. http://www.rki.de/DE/Content/ Gesundheitsmonitoring/Gesundheitsberichterstattung/GBEDownloadsB/ GEDA12.pdf?_blob=publicationFile. Accessed 11 Feb 2015.

10. Reuss AM, Walter D, Feig M, Kappelmeyer L, Buchholz U, Eckmanns T, et al. Influenza vaccination coverage in the 2004/05, 2005/06, and 2006/07 seasons: a secondary data analysis based on billing data of the German Associations of Statutory Health Insurance Physicians. Dtsch Arztbl Int. 2010;107(48):845-50.

11. Waksberg J. Sampling methods for random digit dialing. JASA. 1978;73(361):40-6.

12. Gabler S, Häder S. Idiosyncrasies in telephone sampling-the case of Germany. Int J Public Opin Res. 2002;14(3):339-45.

13. O'Rourke D, Blair J. Improving random respondent selection in telephone surveys. J Mark Res. 1983;20(4):428-32.

14. Böhmer MM, Walter D, Falkenhorst G, Muters S, Krause G, Wichmann O. Barriers to pandemic influenza vaccination and uptake of seasonal influenza vaccine in the post-pandemic season in Germany. BMC Public Health. 2012;12:938.

15. American Association for Public Opinion Research. 2011. http:// www.esomar.org/uploads/public/knowledge-and-standards/codes-andguidelines/ESOMAR_Standard-Definitions-Final-Dispositions-of-Case-Codesand-Outcome-Rates-for-Surveys.pdf. Accessed 11 Feb 2015.

16. Bödeker B, Walter D, Reiter S, Wichmann O. Cross-sectional study on factors associated with influenza vaccine uptake and pertussis vaccination status among pregnant women in Germany. Vaccine. 2014;32(33):4131-9.

17. Schenk L, Bau AM, Borde T, Butler J, Lampert T, Neuhauser $H$, et al. A basic set of indicators for mapping migrant status. Recommendations for epidemiological practice. Bundesgesundheitsbl Gesundheitsforsch Gesundheitsschutz. 2006:49(9):853-60.

18. German Federal Statistical Office. Zensus 2011 https://www.destatis.de. Accessed 4 Dec 2014.

19. Public Health England. Flu plan. Winter 2013/2014. 2013. https:/www.gov.uk/ government/uploads/system/uploads/attachment_data/file/225457/ Flu_plan_Winter_2013_to_2014.pdf. Accessed 11 Feb 2015.

20. Bödeker B, Remschmidt C, Muters S, Wichmann O. Influenza, tetanus, and pertussis vaccination coverage among adults in Germany. Bundesgesundheitsbl Gesundheitsforsch Gesundheitsschutz. 2015;58(2):174-81.

21. Jiménez-García R, Rodríguez-Rieiro C, Hernandez-Barrera V, Carrasco Garrido P, López de Andres A, Esteban-Vasallo MD, et al. Negative trends from 2008/9 to 2011/12 seasons in influenza vaccination coverages among high risk subjects and health care workers in Spain. Vaccine. 2014:32(3):350-4.

22. Tuppin P, Choukroun S, Samson S, Weill A, Ricordeau P, Allemand H. Vaccination against seasonal influenza in France in 2010 and 2011: decrease of coverage rates and associated factors. Presse Med. 2012;41(11):e568-76.

23. Pariani E, Amendola A, Piatti A, Anselmi G, Ranghiero A, Bubba L, et al. Ten years (2004-2014) of influenza surveillance in Northern Italy. Hum Vaccin Immunother. 2015;11(1):198-205.

24. Czarkowski MP, Hallmann-Szelinska E, Staszewska E, Bednarska K, Kondratiuk K, Brydak LB. Influenza in Poland in 2011-2012 and in 2011/2012 and 2012/ 2013 epidemic seasons. Przegl Epidemiol. 2014;68(3):455-63.

25. Jimenez-Garcia R, Esteban-Vasallo MD, Rodriguez-Rieiro C, Hernandez-Barrera V, Dominguez-Berjon MA, Carrasco Garrido P, et al. Coverage and predictors of vaccination against 2012/13 seasonal influenza in Madrid, Spain: analysis of population-based computerized immunization registries and clinical records. Hum Vaccin Immunother. 2014;10(2):449-55. doi:10.4161/hv.27152.

26. Public Health England. Influenza immunisation programme for England. GP patient groups. Data collection survey. Season 2013/14. 2014. https://www.gov.uk/government/uploads/system/uploads/attachment_data/ file/319694/2902494_FluVaccineUptake_GPPatients2013-14_acc.pdf. Accessed 4 Apr 2015.

27. Suresh PS, Thejaswini V, Rajan T. Factors associated with 2009 pandemic influenza A (H1N1) vaccination acceptance among university students from India during the post-pandemic phase. BMC Infect Dis. 2011;11:205.

28. Bults M, Beaujean DJ, de Zwart O, Kok G, van Empelen P, van Steenbergen $J \mathrm{E}$, et al. [Mexican flu: risk perception in the general public, precautionary measures and trust in information provided by the government]. Ned Tijdschr Geneeskd. 2010;154:A1686.

29. Dube E, Gagnon D, Kiely M, Defay F, Guay M, Boulianne N, et al. Seasonal influenza vaccination uptake in Quebec, Canada, 2 years after the influenza A(H1N1) pandemic. Am J Infect Control. 2014;42(5):e55-9. 
30. Kroneman M, van Essen GA, John PW. Influenza vaccination coverage and reasons to refrain among high-risk persons in four European countries. Vaccine. 2006;24(5):622-8.

31. Tsui HY, Lau JT, Lin C, Choi KC. Prevalence of seasonal influenza vaccination and associated factors in people with chronic diseases in Hong Kong. Epidemiol Infect. 2013;141(2):377-89.

32. Nagata JM, Hernandez-Ramos I, Kurup AS, Albrecht D, Vivas-Torrealba C, Franco-Paredes C. Social determinants of health and seasonal influenza vaccination in adults $>/=65$ years: a systematic review of qualitative and quantitative data. BMC Public Health. 2013;13:388.

33. Mclntyre A, Zecevic A, Diachun L. Influenza vaccinations: older adults' decision-making process. Can J Aging. 2014;33(1):92-8.

34. Evans MR, Prout $H$, Prior L, Tapper-Jones LM, Butler CC. A qualitative study of lay beliefs about influenza immunisation in older people. Br J Gen Pract 2007;57(538):352-8.

35. Bundeszentrale für gesundheitliche Aufklärung. Einstellungen, Wissen und Verhalten der Allgemeinbevölkerung zu Hygiene und Infektionsschutz. 2013. http://www.bzga.de/forschung/studien-untersuchungen/studien/impfenund-hygiene/?sub=79. Accessed 11 Feb 2015.

36. Meyer C, Reiter S. Vaccine opponents and sceptics. History, background, arguments, interaction. Bundesgesundheitsbl Gesundheitsforsch Gesundheitsschutz. 2004;47(12):1182-8.

37. Gaczkowska A, Mertens B, Reckendrees B, Wortberg S, Pott E. Knowledge, attitude, and practice concerning measles vaccination. Approaches for national vaccination education. Bundesgesundheitsbl Gesundheitsforsch Gesundheitsschutz. 2013;56(9):1270-8.

38. Böhmer MM, Walter D, Muters S, Krause G, Wichmann O. Seasonal influenza vaccine uptake in Germany 2007/2008 and 2008/2009: results from a national health update survey. Vaccine. 2011;29(27):4492-8.

39. Kwong EW, Pang SM, Choi PP, Wong TK. Influenza vaccine preference and uptake among older people in nine countries. J Adv Nurs. 2010;66(10):2297-308.

40. Lau JT, Yang $X$, Tsui HY, Kim JH. Prevalence of influenza vaccination and associated factors among community-dwelling Hong Kong residents of age 65 or above. Vaccine. 2006;24(26):5526-34.

41. Keenan $\mathrm{H}$, Campbell J, Evans PH. Influenza vaccination in patients with asthma: why is the uptake so low? Br J Gen Pract. 2007:57(538):359-63.

42. Wheelock A, Thomson A, Sevdalis N. Social and psychological factors underlying adult vaccination behavior: lessons from seasonal influenza vaccination in the US and the UK. Expert Rev Vaccines. 2013;12(8):893-901.

43. Ward L, Draper J. A review of the factors involved in older people's decision making with regard to influenza vaccination: a literature review. J Clin Nurs. 2008;17(1):5-16.

44. Betsch C, Schmid P. Does fear affect the willingness to be vaccinated? The influence of cognitive and affective aspects of risk perception during outbreaks. Bundesgesundheitsbl Gesundheitsforsch Gesundheitsschutz. 2013;56(1):124-30.

45. Betsch C, Wicker S. E-health use, vaccination knowledge and perception of own risk: drivers of vaccination uptake in medical students. Vaccine 2012;30(6):1143-8.

46. Brewer NT, Chapman GB, Gibbons FX, Gerrard M, McCaul KD, Weinstein ND. Meta-analysis of the relationship between risk perception and health behavior: the example of vaccination. Health Psychol. 2007;26(2):136-45.

47. Böhmer MM, Walter D, Krause G, Muters S, Gosswald A, Wichmann O. Determinants of tetanus and seasonal influenza vaccine uptake in adults living in Germany. HumVaccin. 2011;7(12):1317-25.

48. Wiese-Posselt M, Leitmeyer K, Hamouda O, Bocter N, Zollner I, Haas W, et al. Influenza vaccination coverage in adults belonging to defined target groups, Germany, 2003/2004. Vaccine. 2006;24(14):2560-6.

49. Mangtani $P$, Shah A, Roberts JA. Validation of influenza and pneumococcal vaccine status in adults based on self-report. Epidemiol Infect. 2007;135(1):139-43.

50. Nichol KL, Korn JE, Baum P. Estimation of outpatient risk characteristics and influenza vaccination status: validation of a self-administered questionnaire. Am J Prev Med. 1991;7(4):199-203.
51. Minor DS, Eubanks JT, Butler Jr KR, Wofford MR, Penman AD, Replogle WH. Improving influenza vaccination rates by targeting individuals not seeking early seasonal vaccination. Am J Med. 2010;123(11):1031-5.

52. Stockwell MS, Kharbanda EO, Martinez RA, Vargas CY, Vawdrey DK, Camargo S. Effect of a text messaging intervention on influenza vaccination in an urban, low-income pediatric and adolescent population: a randomized controlled trial. JAMA. 2012;307(16):1702-8.

\section{Submit your next manuscript to BioMed Central and take full advantage of:}

- Convenient online submission

- Thorough peer review

- No space constraints or color figure charges

- Immediate publication on acceptance

- Inclusion in PubMed, CAS, Scopus and Google Scholar

- Research which is freely available for redistribution

Submit your manuscript at www.biomedcentral.com/submit 